\title{
APLIKASI PENGENALAN KEBUDAYAAN JAWA BERBASIS DESKTOP
}

\author{
Adika May Sari ${ }^{1}$, Rina Lestari ${ }^{2}$, Desri Yani $^{3}$, Rosmita $^{4}$ \\ ${ }^{1,3}$ Sistem Informasi, Fakultas Tehnologi Informasi \\ ${ }^{2}$ Bahasa Inggris, Fakultas Komunikasi dan Bahasa \\ ${ }^{4}$ Sistem Informasi Akuntansi, Fakultas Sistem Informasi \\ Universitas Bina Sarana Informatika \\ adika.dik@bsi.ac.id ${ }^{1}$, rina.rls@bsi.ac.id ${ }^{2}$, desriyani.dsr@bsi.ac.id ${ }^{3}$, rosmita.rmt@bsi.ac.id ${ }^{4}$
}

\begin{abstract}
Nowadays, technology has a big impact for lifes. It also makes children like to use technology to watch videos, play games and socialize through the media. In addition to that technology, they are more familiar with foreign culture compared to their own culture. The habit itself is very related to daily activities using smart phones via the internet. Likewise, the introduction of culture in Java for dekstopbased elementary school children is still very rare today. The making of this application is a solution to provide knowledge about diverse cultures in Java. With this application it is hoped that children will get to know their own country's culture more than foreign cultures. Thus, it can create a feeling of love for the nation itself. The dekstop application that is served is an application that supports a culture consisting of various menus to facilitate users who open this application with those connected to the internet, using a system development method called waterfall which is system planning, system design, code conversion, system testing and good assistance. In this research, an application in dekstop platform was successfully created and from the evaluation it is useful for children and students in learning Java culture.
\end{abstract}

Keywords: Desktop, Java, Culture, Waterfall

\begin{abstract}
ABSTRAK
Semakin mudah teknologi di gunakan saat ini, membuat banyak anak lebih suka menggunakan teknologi untuk menonton video, bermain game dan bersosialisasi melalui media. Tetapi dengan kemudahan teknologi ini, mereka lebih akrab dengan budaya asing daripada budaya mereka sendiri. Kebiasaan itu sendiri sangat erat kaitannya dengan aktivitas sehari hari yang selalu menggunakan ponsel pintar melalui jaringan internet. Begitu juga dengan pengenalan budaya di pulau Jawa untuk anak-anak sekolah dasar berbasis desktop masih sangat langka saat ini. Pembuatan aplikasi ini merupakan solusi untuk memberikan pengetahuan tentang beraneka ragam nya budaya di Pulau Jawa. Dengan adanya aplikasi ini diharapkan anak-anak lebih mengenal budaya Negara sendiri di banding budaya asing. Dengan demikian dapat menimbulkan rasa cinta terhadap bangsa sendiri. Aplikasi desktop yang disuguhkan adalah sebuah aplikasi pengenalan budaya yang terdiri dari berbagai menu untuk memudahkan user membuka aplikasi ini tanpa harus terhubung dengan internet, dengan menggunakan metode pengembangan perangkat lunak waterfall yaitu perencanaan sistem, desain sistem, penulisan kode, pengujian sistem dan pemeliharaan yang baik agar dapat dikembangkan kembali.
\end{abstract}

Kata Kunci: Desktop, Budaya, Jawa, Waterfall

DOI: http://dx.doi.org/10.15408/jti.v12i2.11077 


\section{PENDAhuluan}

Saat ini Indonesia terbagi atas 34 Provinsi serta memiliki beraneka ragam budaya. Dari beranekaragamannya budaya serta banyaknya wilayah atau provinsi dan banyaknya populasi penduduk adalah tidak menutupi kemungkinan bahwa tidak semua masyarakat Indonesia terutama anak-anak mampu mengenali dan mengetahui dengan jelas tentang keseluruhan wilayah dan budaya Indonesia dengan baik [1].

Pendidikan mengenai kesenian daerah sebagian besar hanya diberikan di sekolah dengan porsi yang sedikit [2]. Kebanyakan guru hanya menggunakan buku sebagai panduan dan menjelaskan secara ringkas. Sehingga anakanak sebagai peserta ajar merasa jenuh dengan pendidikan yang disampaikan oleh guru dan menimbulkan kurangnya minat belajar bagi mereka. Kurangnya minat belajar bagi para anak-anak peserta ajar tentunya menjadi masalah bagi para orang tua di rumah untuk meningkatkan semangat belajar bagi anakanaknya.

Masalah ini dapat diatasi dengan pembuatan aplikasi berbasis dekstop tentang pengenalan berbagai macam budaya di Indonesia khususnya di Pulau Jawa, sebagai media yang bisa memberikan edukasi terhadap anak-anak Sekolah Dasar tentang budaya yang meliputi senjata tradisional, pakaian tradisional dan tarian tradisional. Oleh sebab itu, diharapkan program aplikasi ini dapat memberikan pengetahuan tentang beberapa budaya yang ada di Pulau Jawa kepada anakanak Sekolah Dasar. Adapun tujuan nya adalah agar para siswa Sekolah Dasar dapat mengenal banyaknya budaya di Pulau Jawa yang beraneka ragam dengan menggunakan media komputer berbasis desktop agar lebih menyenangkan sehingga bisa menimbulkan minat belajar yang tinggi. Diharapkan generasi berikutnya bisa ikut mewariskan dan melestarikan budaya yang ada.

Beberapa penelitian sejenis telah dilakukan oleh [1], [2], [3], [4]. Penelitianpenelitian sebelumnya menggunakan metode pengembangan mobile program Android atau mobile learning. Pada penelitian ini, aplikasi dikembangkan menggunakan metode pengembangan sistem Waterfall dan berbasis dekstop. Pemilihan platform desktop disesuaikan dengan kebutuhan aplikasi ini sebagai media pembelajaran atau pengenalan kebudayaan kepada siswa, dimana banyaknya gambar dan keterangan yang menyertai tampilan aplikasi akan lebih mudah dibaca oleh siswa dalam tampilan dekstop yang relatif lebih besar dari pada media smartphone.

Paper ini ditulis dalam beberapa bagian, yaitu bagian 1 adalah pendahuluan, bagian 2 adalah metodologi, bagian 3 membahas tentang hasil dan pembahasan mengenai hal tersebut, bagian 4 merupakan penutup dari paper ini.

\section{METODOLOGI}

\subsection{Metode Pengembangan Perangkat Lunak}

Metode yang digunakan pada pengembangan perangkat lunak ini menggunakan model waterfall yang terbagi menjadi empat tahapan, yaitu:

a. Analisis Kebutuhan Perangkat Lunak

Tahapan ini sangat menekan pada masalah pengumpulan kebutuhan pengguna pada tingkatan system dengan menentukan konsep. Seperti keragaman Pulau Jawa yang terdiri dari beberapa menu antara lain, makanan khas, rumah adat.

\section{b. Desain}

Proses desain ini akan menerjemaahkan syarat kebutuhan ke sebuah perancangan software yang dapat diperkirakan sebelum pembuatan program dilakukan, proses ini berfokus pada rancangan arsitektur software, interface, dan detail (algoritma) procedural. Tahapan ini menghasilkan dokumen yang disebut software requirement. Proses perancangan system ini dengan menggunakan HIPO (Hierarcy Input Proses Output).

\section{c. Pembuatan Kode Program}

Pada tahapan ini adalah pembuatan kode program yang digunakan dalam mentranslasikan tahapan sebelumnya. Kode program yang digunakan adalah $\mathrm{C \#}$. Bahasa $\mathrm{C \#}$ sangat cocok untuk digunakan pada aplikasi dekstop ini, Visual Studio menyertakan editor kode intelliSense serta refactoring code, debugger terintegrasi berfungsi baik sebagai debugger tingkat sumber maupun debugger tingkat mesin. Alat bawaan termasuk perancang formulir untuk membangun aplikasi GUI.

\section{d. Pengujian}

Pada tahap ini, merupakan tahap akhir dalam pengembangan perangkat lunak, yang dilakukan untuk meminimalisir kesalahan 
(error) dan memastikan keluaran yang dihasilkan sesuai dengan yang diinginkan. Tahap pengujian ini menggunakan black box testing.

\subsection{Metode Pengumpulan Data}

Dalam proses pembuatan aplikasi ini menggunakan beberapa metode yang memudahkan penulis dalam pembuatan aplikasi, dimana metode tersebut yaitu:

\section{a. Observasi}

Melakukan metode pengamatan dan mencari informasi dengan survei ke beberapa sekolah dasar yang ada di Jakarta, adalah salah satu teknik pengumpulan data yang cukup efektif untuk mempelajari suatu system berbasis dekstop. Observasi merupakan pengumpulan data dengan cara sistematik. Untuk mendapatkan observasi secara sistematis peneliti harus mempunyai latar belakang pengetahuan dan ketrampilan yang luas tentang obyek penelitian. Observasi yang dilakukan pada penelitian ini yaitu dengan meneliti sistem belajar mengajar yaitu di beberapa Sekolah Dasar

\section{b. Studi Kepustakaan}

Untuk mendukung selesainya pembuatan aplikasi pembelajaran ini, maka dilakukan studi kepustakaan melalui berbagai buku-buku bacaan yang berhubungan dengan penulisan Pengumpulan data, seperti dengan menggunakan atau mengumpulkan sumbersumber tertulis, dengan cara membaca, dan mencatat hal-hal penting dari buku dan jurnal yang ebook maupun cetak yang berhubungan dengan masalah yang sedang dibahas guna memperoleh gambaran secara teoritis yang dapat menunjang pada penyusunan penelitian.

\section{HASIL DAN PEMBAHASAN}

Dalam merancang program dibutuhkan dokumen masukkan yang akan diproses untuk menghasilkan suatu dokumen keluaran yang baik. Berikut ini beberapa spesifikasi rancangan program yang dibuat:

\subsection{Spesifikasi Dokumen Masukan}

1. Menu Utama

- Nama : Menu Utama

- Fungsi : Menampilkan menu pilihan Budaya

- Sumber : Pengguna
- Tujuan : Pengguna

- Media : button

- Frekuensi : Setiap pengguna ingin memulai aplikasi

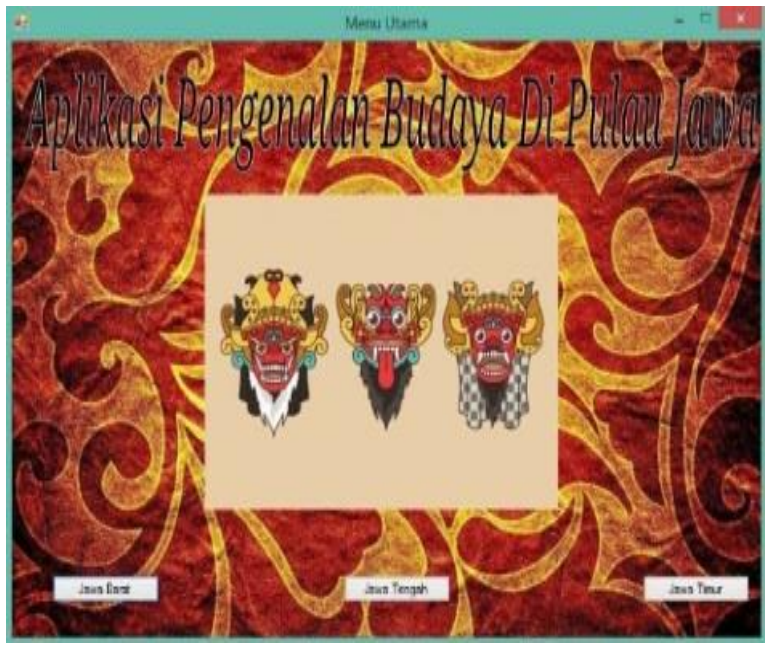

Gambar 1. Menu utama

2. Menu Kebudayaan Jawa Barat

- Nama : Kebudayaan Jawa Barat

- Fungsi : Menampilkan makanan, pakaian dan kesenian

- Sumber : Pengguna

- Tujuan : Pengguna

- Media : button, PictureBox

- Frekuensi : Setiap pengguna ingin membuka aplikasi

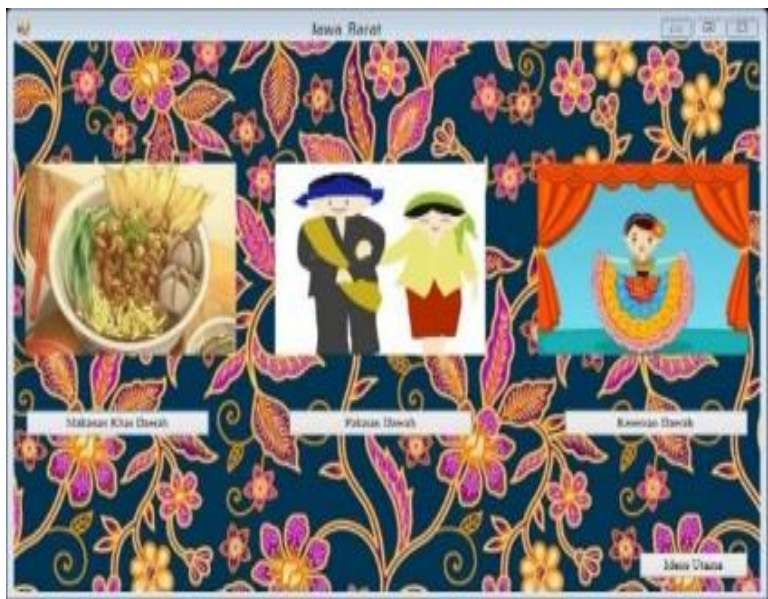

Gambar 2. Menu kebudayaan Jawa Barat

\subsection{Spesifikasi Dokumen Keluaran}

1. Menu makanan Khas Daerah

- Fungsi : Menampilkan penjelasan tentang karedok

- Sumber : Pengguna

- Tujuan : Pengguna

- Media : picturebox, button, textbox 
- Frekuensi : ketika pengguna ingin menampilkan penjelasan tentang karedok

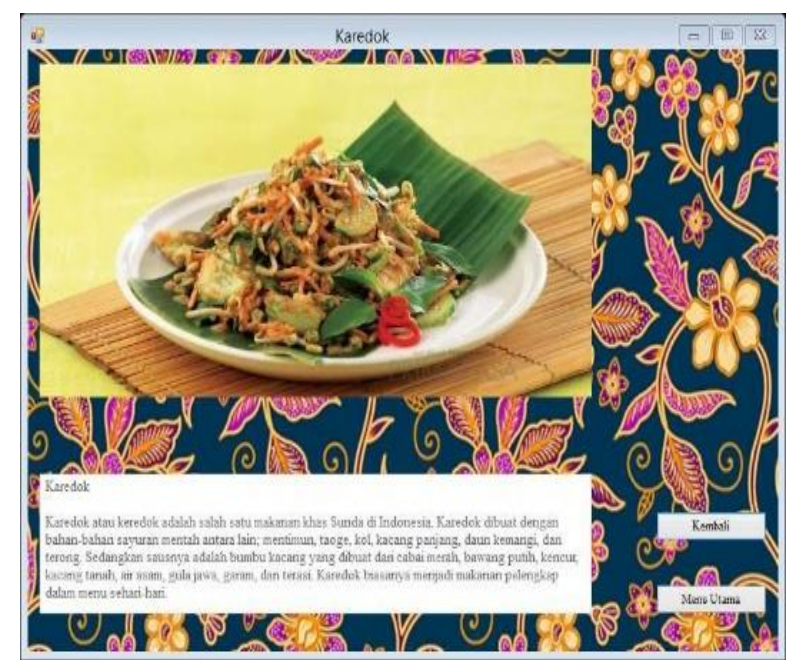

Gambar 3. Makanan khas daerah

2. Menu makanan Khas Daerah

- Fungsi : menampilkan penjelasan tentang serabi

- Sumber : Pengguna

- Tujuan : Pengguna

- Media : picturebox, button, textbox

- Frekuensi : ketika pengguna ingin menampilkan penjelasan tentang serabi

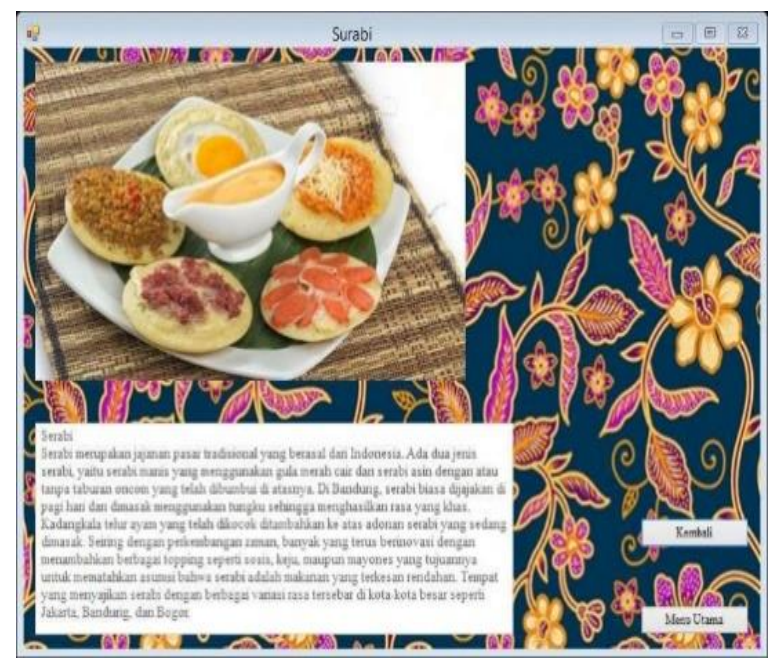

Gambar 4. Menu makanan khas 


\subsection{HIPO}

Berikut ini ditampilkan diagram HIPO (Hierarchical Input Process Output) yang digunakan dalam membantu mengembangkan aplikasi.

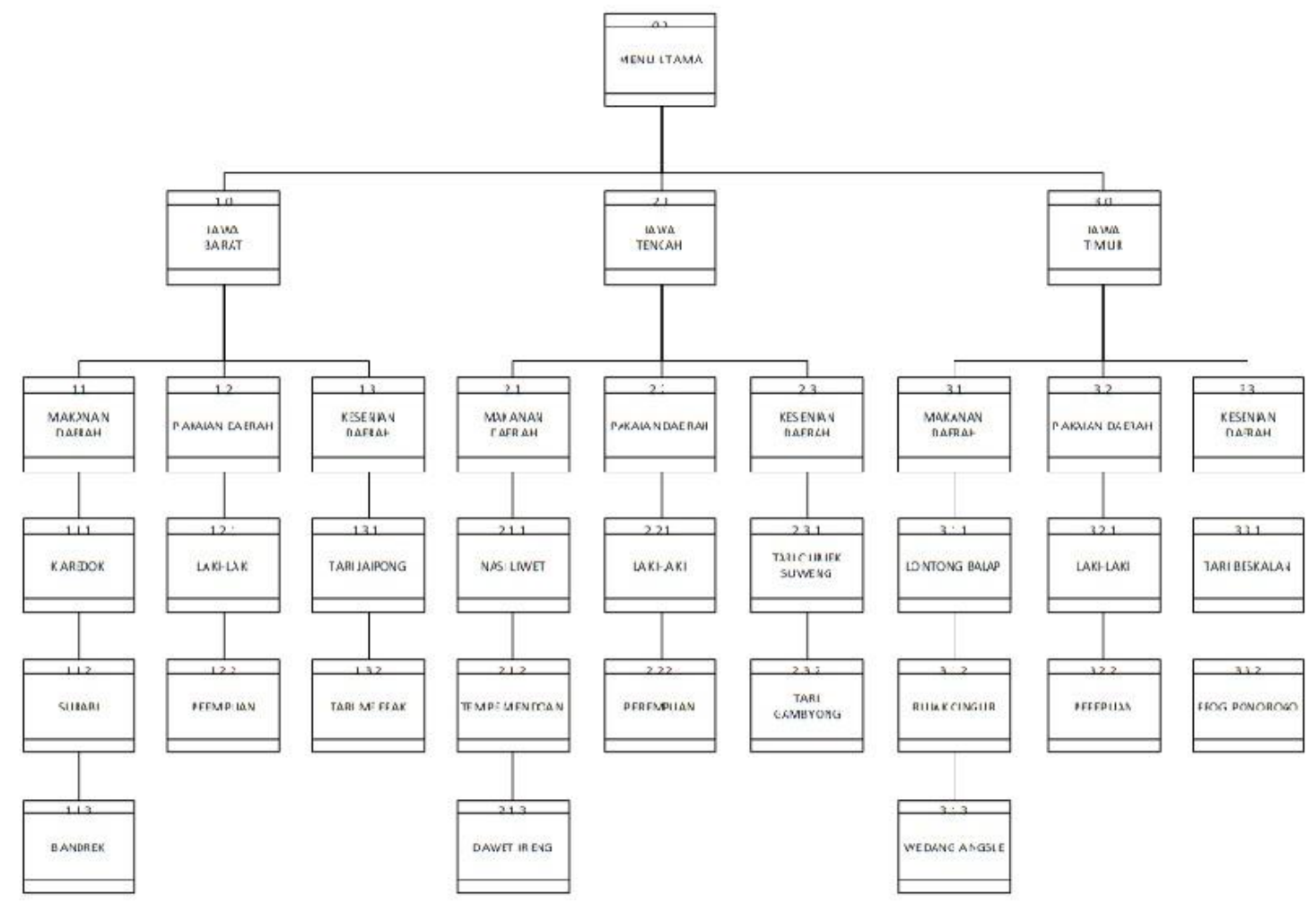

Gambar 5. Diagram HIPO 


\subsection{Flowchart}

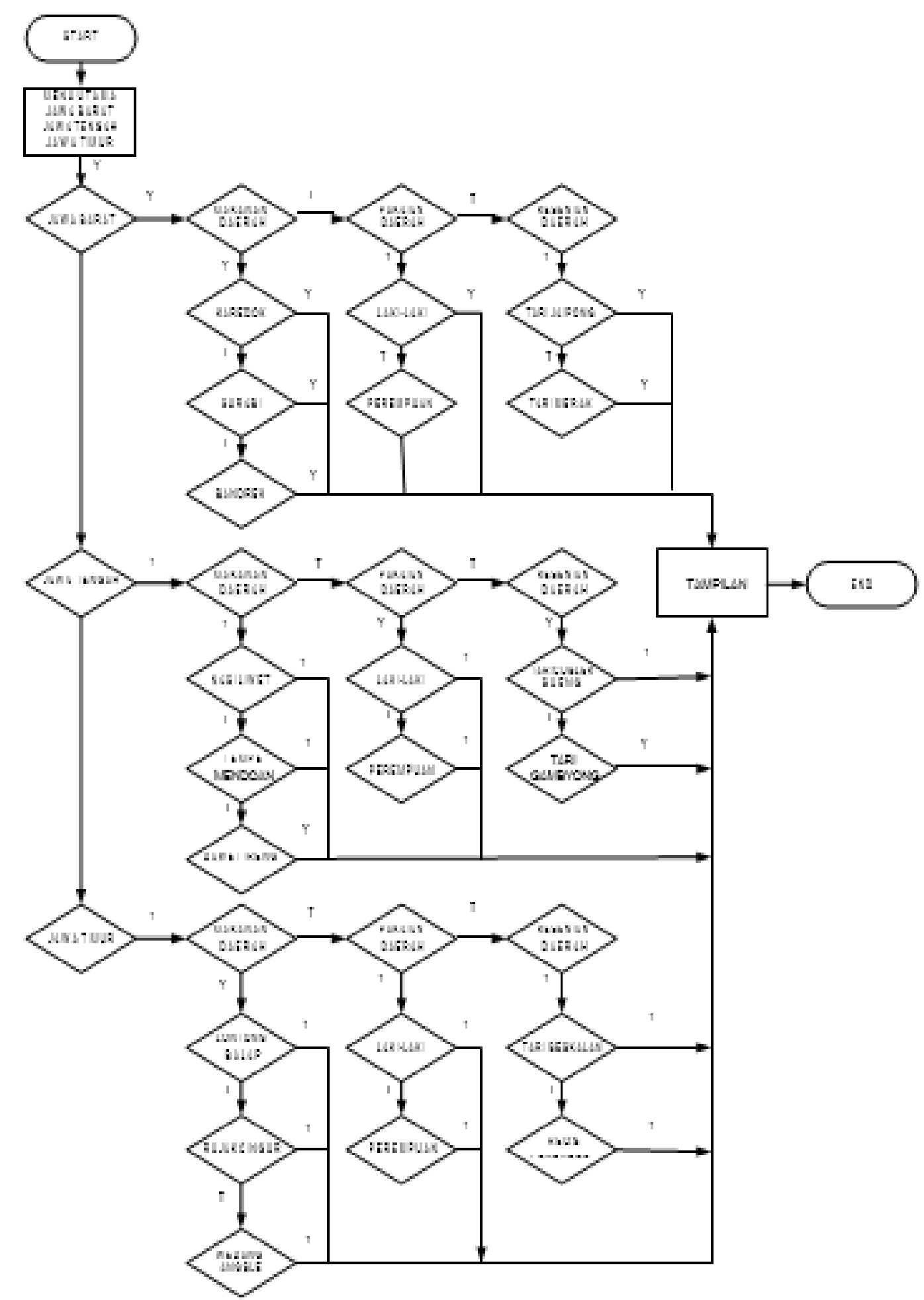

Gambar 6. Flowchart

3.5 Hasil Pengujian Black Box Testing Pada Halaman Dekstop Aplikasi
Pengujian dilakukan terhadap program yang dibuat menggunakan blackbox testing yang fokus terhadap proses masukan dan 
keluaran program untuk mengetahui kekurangan dari program dan program berjalan sesuai dengan yang diharapkan.
Tabel 1 berikut merupakan hasil pengujian black box pada halaman menu utama.

Tabel 1. Pengujian black box testing pada halaman menu utama

\begin{tabular}{|c|c|c|c|c|c|}
\hline No. & Skenario Pengujian & Test Case & $\begin{array}{l}\text { Hasil yang } \\
\text { diharapkan }\end{array}$ & Hasil Pengujian & Kesimpulan \\
\hline 1 & $\begin{array}{l}\text { Halaman Utama } \\
\text { Menampilkan Aplikasi } \\
\text { pengenalan Budaya } \\
\text { Di Pulau Jawa dimana } \\
\text { terdapat Menu utama } \\
\text { Yang terdiri dari Menu } \\
\text { Jawa Barat, Menu Jawa } \\
\text { Tengah dan menu Jawa } \\
\text { Timur }\end{array}$ & $\begin{array}{ll}\text { Diberikan } & \text { input } \\
\text { klik menu Jawa } \\
\text { Barat }\end{array}$ & $\begin{array}{l}\text { Akan menampilkan } \\
\text { kebudayaan daerah } \\
\text { Jawa Barat yang } \\
\text { terdiri dari } \\
\text { Makanan khas } \\
\text { daerah Jawa Barat, } \\
\text { pakaian, dan tarian } \\
\text { dari daerah Jawa } \\
\text { Barat. }\end{array}$ & Sesuai Harapan & Valid \\
\hline 2 & $\begin{array}{lr}\text { Halaman } & \text { menu } \\
\text { makanan khas daerah } \\
\text { Jawa Barat }\end{array}$ & $\begin{array}{lr}\text { Diberikan } & \text { input } \\
\text { klik pada } & \text { menu } \\
\text { makanan } & \text { khas } \\
\text { daerah } & \\
\text { Jawa Barat } & \end{array}$ & \begin{tabular}{lr}
\multicolumn{2}{l}{ Menampilkan } \\
penjelasan & tentang \\
makanan & daerah \\
Jawa Barat &
\end{tabular} & Sesuai Harapan & Valid \\
\hline 3 & $\begin{array}{l}\text { Halaman menu tarian } \\
\text { khas daerah Jawa Barat }\end{array}$ & $\begin{array}{l}\text { Di berikan input } \\
\text { klik pada menu } \\
\text { tarian khas daerah } \\
\text { Jawa Barat }\end{array}$ & $\begin{array}{l}\text { Menampilkan } \\
\text { penjelasan tentang } \\
\text { tarian khas daerah } \\
\text { Jawa Barat }\end{array}$ & Sesuai Harapan & Valid \\
\hline
\end{tabular}

\section{PENUTUP}

Kesimpulan pada penelitian ini

1. Aplikasi dekstop kebudayaan ini adalah suatu aplikasi yang mampu beroperasi secara offline, tetapi kita harus menginstalnya sendiri pada laptop atau komputer. Aplikasi sebelumnya berupa aplikasi kebudayaan web yang mengharuskan pengguna terhubung dengan internet.

2. Aplikasi dekstop pengenalan beragam budaya di pulau Jawa untuk anak sekolah dasar memberikan kelebihan tersendiri pada siswa sekolah dasar yang biasanya, yang biasanya mereka hanya belajar melalui buku ataupun dengan browsing pada beberapa web tentang kebudayaan.

3. Untuk membangun sebuah aplikasi dekstop diperlukan adanya hardware, software, dan brainware yang tepat sehingga dapat tercipta suatu sistem yang telah direncanakan. Dekstop based adalah aplikasi berbasis dekstop yang berjalan di satu atau beberapa komputer (terhubung dalam satu jaringan) secara independen dan tidak memerlukan browser.

\section{DAFTAR PUSTAKA}

[1] Rendrahadi, Rendrahadi, et al., "Aplikasi Pembelajaran Pengenalan Budaya Indonesia Pada Mobile Device Berbasis Android", in Jurnal Infra, 2017.

[2] Tresnawati, D. dan Nugraha, T.S, "Pengembangan Aplikasi Pengenalan Kesenian Indonesia sebagai Media Pembelajaran Berbasis Android", in Jurnal Algoritma, Sekolah Tinggi Teknologi Garut Vol 12 No. 1, 2015.

[3] Rahman, F. dan Santoso, S, "Aplikasi Pemesanan Undangan Online", in Jurnal Sains dan Informatika, Vol. 1 No. 2, Universitas Politala, 2017.

[4] Wibowo, D.A, dan Hendra, D. "Aplikasi Objek Wisata Berbasis Smartphone Android" in Jurnal Teknik, Universitas Muhamadiyah Tangerang, 2015.

[5] Habibie, F.H.,'Pembangunan Sistem Informasi Penerimaan Calon Tenaga Kerja Secara Online Berbasis Web Pada 
Bursa Kerja Khusus SMK Ganesha Tama Boyolali”, in Jurnal Speed Vol. 9 No. 2, FTI UNSA, 2012.

[6] Irawan, Membuat Aplikasi Android untuk Orang Awam, Palembang: Maxicom, 2012.
[7] Putri, N.E, "Sistem Informasi Pengolahan Data Pendidikan Anak Usia Dini (PAUD) Terpadu Amalia Syukra Padang" in Jurnal Edik Informatika, Vol 2 No. 2, 2016. 